\title{
Evaluation of Analytical Quality of Cardiac Biomarkers in the Emergency Laboratory by Sigma Metric
}

\author{
Saadet Kader \\ Karapinar State Hospital Biochemistry Laboratory Karapinar, Konya, Turkey \\ E-mail: saadetkader@hotmail.com
}

\begin{abstract}
Objectives: The Six-Sigma Methodology is a quality measurement method in order to evaluate the performance of the laboratory. In the present study, we aimed to evaluate the analytical performance of our emergency laboratory by using the internal quality control data of cardiac biomarkers and by calculating process sigma values.

Materials and Methods: Biological variation database (BVD) are used for Total Allowable Error (TEa). Sigma values were determined from coefficient of variation (CV) and bias resulting from Internal Quality Control (IQC) results for 4 subsequent months. If the sigma values are $\geq 6$, between 3 and 6 , and $<3$, they are classified as »world-class «, »good « or »un -acceptable«,respectively .

Results: When the sigma values were analyzed by calculating the mean of 4 months,

Troponin I (cTnI), CKMB mass, Myoglobin $(\mathrm{Mb})$ were found $<3$.

Conclusions: The "poor quality" levels of cTnT, CKMB mass, Myoglobin sigma values, decision is taken for the improvement of cardiac markers in our laboratory. It is possible to determine the test with high error probability by evaluating the fine sigma levels and the tests that must be quarded by a stringent quality control regime. In clinical chemistry laboratories, an appropriate quality control scheduling should be done for each test by using Six-Sigma Methodology.
\end{abstract}

Keywords: Six Sigma, total allowable error, bias, Cardiac Biomarkers

DOI: $10.7176 / J S T R / 5-9-05$

\section{Introduction}

In the health care sector, laboratory test results are of really important for decision-making.

Approximately two-thirds of important clinical decisions on patient management based on the clinical laboratory (1). So, continuous improvement and the minimizing of errors in testing are the major goals of every clinical laboratory.

The Six-Sigma Methodology may be used to evaluate the quality of the analytical phase by combining bias, imprecision and allowable total error (TEa) (2). TEa is a useful parameter for determinating required laboratory test quality which combines the effects of systematic and random errors and Imprecision is usually expressed as standard deviation (SD) or coefficient of variation (CV). (3). The clinical application of Six-Sigma quality management involves the combined use of quality requirements and laboratory performance to quantitatively evaluate whether a laboratory meets clinical testing standards. This evaluation is typically based on the expected defect rate. The ultimate goal of $6 \sigma$ quality management is to implement laboratory risk management and thus ensure patient safety (4). Several studies on the application of $6 \sigma$ management in laboratory testing have been reported, including studies on theoretical methods and their significance, the evaluation of performance of different assays, and the optimization of quality control (QC) schedules based on performance evaluation (5-7). According to Nevalainen and his friends, "average products, regardless of their complexity, have a quality performance value of about $4 \sigma$. The best, or 'world class quality,' products have a level of performance of $6 \sigma$ " (8). Thus, laboratories should be aware of such sources of variation when $\sigma$ management is applied, as they may modulate the value of $\sigma$ and the accuracy of $\sigma$ measurement. Six Sigma metrics can serve as a self-assessment method in guiding clinical laboratory to make QC strategy and plan QC frequency. It's very helpful to implement this metrics into clinical laboratory daily analytical processes in order to produce accurate test results. High sigma values means low analytical errors and acceptable test results (9). Low sigma metric value is accepted as an error or a defect. The defect value is measured in defects per million (DPM) (10). The Six-Sigma is focused to control a process in 6 standard deviations (SD) and it is equal to 3.4 DPM. The success with Six Sigma Quality is accepted as the perfection standard. A performance at the 3-sigma 
level is considered as the minimum quality for manufacturing process $(11,14)$. In the present study, we aimed to evaluate the analytical performance of our emergency laboratory by using the internal quality control data of cardiac biomarkers and by calculating process sigma values.

\section{Materials and Methods}

The present study was conducted in the clinical chemistry laboratory of the Karapınar State Hospital. Internal quality control (IQC) data of 3 analytes were analyzed retrospectively over a period of 4 months from January 2019 to April 2019 using Siemens Advia Centaur Classic (Siemens Healthcare Diagnostics, Tarrytown, NY, USA). 3 serum cardiac tests were included: Troponin I (cTnI), CKMB mass, Myoglobin $(\mathrm{Mb})$. All reagents were obtained from Siemens and used according to the manufacturer's package inserts.

Both normal (IQC1) and pathological (IQC2) levels of QC materials were assayed before analysing of patient samples every day. Serocheck NormControl and Serocheck PathControl QC materials were belong to Serocon Diagnostics company (Konya, Turkey) and QC values were based on the reference method. The instruments was calibrated regularly. IQC data were obtained from Laboratory Data Management System. Faulty values arising from false

control samples were excluded. Following the determination of mean and SD values, CV, bias and sigma values were calculated according to the following formulations. The target mean, labaratory mean and $\mathrm{SD}$ values of each test are presented in Table I.

\subsection{Coefficient of variation calculation}

Imprecision, expressed as coefficient of variation $(\% \mathrm{CV})$ was determined from the calculated mean and Standard deviation evaluated from internal quality control (IQC) data.

$\mathrm{CV}$ is the ratio of the SD which is obtained from a data set to the mean $(\overline{\mathrm{x}})$ and it is expressed as a percentage of variance to the mean; $\mathrm{CV}(\%)=(\mathrm{SD} /$ Mean of IQC data $) \times 100$.

\subsection{Determination of Bias}

Bias was calculated as the percentage difference of the average of observed results for each analyte from the target values provided in the roche control package inserts. Percent bias values of each test were calculated separately between January, February, March and April

2019.

$\%$ Bias $=[$ (our laboratory mean of IQC data-target mean of IQC data)/target mean of IQC data $] \times 100$

\subsection{Allowable total error (TEa)}

The sigma metrics were calculated using TEa goals from one source in order to understand the effect of TEa on estimates of Sigma metrics: the Desirable Biological Variation Database (15). These source is regularly updated and can be freely accessed through http://www.westgard.com. The TEa values of each test are presented in Table II.

\subsection{Sigma metric calculation}

Sigma (s) value was used in order to determine the analytical performance characteristics of sigma value tests by using CV (obtained from IQC data), Bias\% and TEa values. Sigma value calculated using the standard equation: Sigma metric $(\mathrm{s})=(\% \mathrm{TEa}-\% \mathrm{Bias}) / \% \mathrm{CV}$

Sigma values were used to determine the analytical performance characteristics of the test. A sigma level $<3$ is an indication of a poor performance procedure, whilst a good performance is indicated by a sigma level $>3$. Above six sigma level is a world class performance (16).

\section{Results}

Table I shows the target mean, laboratory mean and the calculated standard deviation values of the two levels namely normal (IQC1) and pathological (IQC2) quality controls run in our laboratory for the different parameters.

Table II shows TEa, bias and coefficient of variation (CV) sigma values of the two levels of quality control for the different parameters. The $\% \mathrm{CV}$ values of pathological and normal level of IQC were found as $>5 \%$ for the tests including Troponin, CK-MB and Miyoglobin for 4 subsequent months.

Table III and Table IV show that complete sigma metrics for 3 assays. The sigma values of Troponin, $\mathrm{CK}-\mathrm{MB}$ and Miyoglobin were found as $<3$. 
Table 1 . The target mean, laboratory mean and SD values of each test.

\begin{tabular}{|c|c|c|c|c|c|c|c|c|c|c|c|c|c|c|c|c|c|c|}
\hline \multirow{3}{*}{ Assay Name } & \multicolumn{9}{|c|}{ IQC 1} & \multicolumn{9}{|c|}{$1 Q C 2$} \\
\hline & \multirow{2}{*}{ Target Mean } & \multicolumn{2}{|l|}{ January } & \multicolumn{2}{|l|}{ February } & \multicolumn{2}{|l|}{ March } & \multicolumn{2}{|l|}{ April } & & \multicolumn{2}{|l|}{ January } & \multicolumn{2}{|l|}{ February } & \multicolumn{2}{|l|}{ March } & \multicolumn{2}{|l|}{ April } \\
\hline & & Lab mean & SD & Lab mean & SD & Lab mean & SD & Lab mean & SD & & Lab mean & $S D$ & Lab mean & SD & Lab mean & SD & Lab mean & SD \\
\hline Troponin & 0,06 & 0,07 & 0,02 & 0,05 & 0,01 & 0,054 & 0,02 & 0,06 & 0,02 & 2,81 & 2,46 & 0,53 & 2,17 & 0,51 & 2,39 & 0,43 & 2,56 & 0,59 \\
\hline CK-MB & 1,23 & 1,65 & 0,32 & 2,06 & 0,39 & 1,87 & 0,32 & 1,99 & 0,13 & 10,41 & 9,86 & 2,17 & 9,71 & 1,52 & 10,7 & 2,11 & 11,02 & 1,62 \\
\hline Miyoglobin & 30,25 & 30,04 & 6,8 & 25,53 & 2,88 & 32,05 & 2,17 & 30,02 & 2,2 & 57,03 & 58,5 & 9,7 & 48,63 & 11,62 & 56,09 & 2,42 & 51,65 & 11,7 \\
\hline
\end{tabular}

Table I shows the target mean, laboratory mean and the calculated standard deviation values of the two levels namely normal (IQC1) and pathological (IQC2) quality controls run in our laboratory for the different parameters.

Table 2. TEa, bias and CV values of the two levels of quality control for the assays.

\begin{tabular}{|c|c|c|c|c|c|c|c|c|c|c|c|c|c|c|c|c|c|}
\hline \multirow{3}{*}{ Assay Name } & \multicolumn{9}{|c|}{ IQC 1} & \multicolumn{8}{|c|}{ IQC 2} \\
\hline & \multirow{2}{*}{ Tea(\%) } & \multicolumn{2}{|c|}{ January } & \multicolumn{2}{|c|}{ February } & \multicolumn{2}{|l|}{ March } & \multicolumn{2}{|l|}{ April } & \multicolumn{2}{|c|}{ January } & \multicolumn{2}{|c|}{ February } & \multicolumn{2}{|c|}{ March } & \multicolumn{2}{|l|}{ April } \\
\hline & & $\% \mathrm{CV}$ & \% Bias & $\% \mathrm{CV}$ & $\%$ Bias & $\% C V$ & $\%$ Bias & $\% \mathrm{CV}$ & $\%$ Bias & $\% \mathrm{CV}$ & $\%$ Bias & $\% \mathrm{CV}$ & $\%$ Bias & $\% C V$ & $\%$ Bias & $\% \mathrm{CV}$ & $\%$ Bias \\
\hline Troponin & 27,91 & 28,57 & 16,66 & 20 & 16,66 & 40 & 16,66 & 33,33 & 1,6 & 21,54 & 12,45 & 23,5 & 22,77 & 12,6 & 2,84 & 23,05 & 8,9 \\
\hline CK-MB & 30,06 & 19,39 & 34,14 & 18,93 & 67,48 & 17,11 & 29,27 & 6,53 & 61,78 & 22,01 & 5,28 & 15,65 & 6,72 & 19,7 & 2,78 & 14,7 & 5,86 \\
\hline Miyoglobin & 19,6 & 22,63 & 0,69 & 11,28 & 14,88 & 6,77 & 5,95 & 7,28 & 0,76 & 16,58 & 2,58 & 28,89 & 14,73 & 23,9 & 1,65 & 22,65 & 9,43 \\
\hline
\end{tabular}

Table 2 shows Tea (Allowable total error), bias and coefficient of variation (CV) sigma values of the two levels of quality control for the different parameters.

Table 3. The sigma metrics for 4 months and overall sigma metrics for the assays.

\begin{tabular}{|c|c|c|c|c|c|c|c|c|c|c|}
\hline \multirow[b]{2}{*}{ Assay Name } & \multicolumn{2}{|c|}{ January } & \multicolumn{2}{|c|}{ February } & \multicolumn{2}{|c|}{ March } & \multicolumn{2}{|c|}{ April } & \multicolumn{2}{|c|}{ overall 4 months sigma metrics } \\
\hline & $\begin{array}{l}\text { IQC } 1 \\
\text { sigma } \\
\text { metrics }\end{array}$ & $\begin{array}{l}\text { IQC } 2 \\
\text { sigma } \\
\text { metrics }\end{array}$ & $\begin{array}{l}\text { IQC } 1 \\
\text { sigma } \\
\text { metrics }\end{array}$ & $\begin{array}{l}\text { IQC } 2 \\
\text { sigma } \\
\text { metrics }\end{array}$ & $\begin{array}{l}\text { IQC } 1 \\
\text { sigma } \\
\text { metrics }\end{array}$ & $\begin{array}{l}\text { IQC } 2 \\
\text { sigma } \\
\text { metrics }\end{array}$ & $\begin{array}{l}\text { IQC } 1 \\
\text { sigma } \\
\text { metrics }\end{array}$ & $\begin{array}{l}\text { IQC } 2 \\
\text { sigma } \\
\text { metrics }\end{array}$ & $\begin{array}{l}\text { IQC } 1 \\
\text { sigma } \\
\text { metrics }\end{array}$ & IQC 2 sigma metrics \\
\hline Troponin & 0,39 & 0,71 & 0,56 & 0,22 & 0,28 & 1,99 & 0,79 & 0,82 & 0,51 & 0,94 \\
\hline CK-MB & 0,21 & 1,13 & 1,98 & 1,49 & 0,05 & 1,38 & 4,85 & 1,65 & 1,78 & 1,41 \\
\hline Miyoglobin & 0,84 & 1,03 & 0,42 & 0,17 & 2,02 & 0,75 & 2,6 & 0,45 & 1,47 & 0,6 \\
\hline
\end{tabular}

Table 3 shows that complete sigma metrics for 3 assays.

Table 4. The distribution of groups and tests according to sigma values.

\begin{tabular}{|c|c|c|c|c|c|c|c|c|}
\hline \multirow{3}{*}{ Sigma metrics } & \multicolumn{7}{|c|}{ IQC 1} & \\
\hline & \multicolumn{2}{|l|}{ January } & \multicolumn{2}{|l|}{ February } & \multicolumn{2}{|l|}{ March } & \multicolumn{2}{|l|}{ April } \\
\hline & IQC 1 & IQC 2 & IQC 1 & IQC 2 & IQC 1 & IQC 2 & IQC 1 & IQC 2 \\
\hline Grup $1(<3)$ & $\begin{array}{l}\text { Troponin, } \\
\text { CK-MB, } \\
\text { Miyoglobin }\end{array}$ & $\begin{array}{l}\text { Troponin, CK } \\
\text { MB, } \\
\text { Miyoglobin }\end{array}$ & $\begin{array}{l}\text { Troponin, CK- } \\
\text { MB, } \\
\text { Miyoglobin }\end{array}$ & $\begin{array}{l}\text { Troponin, } \\
\text { CK-MB, } \\
\text { Miyoglobin }\end{array}$ & \begin{tabular}{|l|} 
Troponin, CK \\
MB, \\
Miyog lobin
\end{tabular} & $\begin{array}{l}\text { Troponin, } \\
\text { CK-MB, } \\
\text { Miyoglobin }\end{array}$ & \begin{tabular}{|l|} 
Troponin, \\
CK-MB, \\
Miyoglobin
\end{tabular} & $\begin{array}{l}\text { Troponin, CK- } \\
\text { MB, } \\
\text { Miyoglobin }\end{array}$ \\
\hline \multicolumn{9}{|l|}{ Grup $2(3-6)$} \\
\hline Grup $3(>6)$ & & & & & & & & \\
\hline
\end{tabular}

Table 4 also shows that complete sigma metrics for 3 assays.

\section{Discussion}

In this study, we analysed 3 parameters over a period of 4 months. Six sigma improves the quality of process outputs by analysing and abolishing the source of defects and reducing variability in manufacturing and business practices. In terms of clinical laboratory, the identification of test with low sigma values $(<3 \sigma)$ indicate that actions should be taken to improve analytic quality or the laboratory should use alternate methods and reagents $(17,18)$.

In a study performed by Ercan et al. (19) found at Beckman Coulter UniCel® DxI800 1mmuno assay system autoanalyzer, sigma values were found as 5.18/6.14, 0.35/1.14, 1.88/0.85 for first and second

36 I P a g e

www.iiste.org 
level IQC, respectively. In another study Gulbahar and her friends (20) performed a study at Roche/Cobas e602 autoanalyzer and they compared the two level IQC sigma values of TSH, FT3 and FT4 with two immunoassay analyzer. When the sigma values were calculated, TSH and FT4 were found as »worldclass « and »unacceptable«, respectively, in both analyzers, and FT3 was found as »unacceptable« and »good « for two level IQC of the first analyzer and the second analyzer, respectively. Aksoy et al. (21) found that the sigma values for AFP, cortisol, ferritin and total PSA were 2,49/ 3,20/3,53/1,21/6,46, respectively, by using the TEa values of DBV database in Beckman Coulter DXI 800 autoanalyzer.

According to our results,For all parameters troponin, CK-MB and miyoglobin sigma values were below 3. Method performance must be improved before the method can be used for further production and two levels of QC with a 13S/22S/R4S/41S rule should be taken twice a day. We should strictly follow internal QC and Westgard multi rules and pay special attention to these cardiac parameters. Further, sigma values could increase by upgrading analysers and better methodologies. Variations between our statistical data and others were due to the difference in QC samples as well as instrument and method differences. For these parameters with low sigma values, we will use the optimized QC strategy for future works. Sigma metrics was calcuated by using TEa, bias and CV. This method is not the ideal way, but the practical way. The ideal ways include using reference materials or comparison with reference methods. The results from clinical laboratory have a large impact on patients' lives. However, there is no particular guideline of rules implementation based on the performance of each test and method, which can cause increase of false rejection and waste of control samples for testing laboratory. So, choosing a specific QC procedure will decrease the false rejection and maximize the error detection (22). Clinical laboratory focus on producing exact test results, so it make sense to implement six sigma metrics into their daily analytical processes. Six Sigma metrics could serve as a self assessment method in guiding clinical laboratory to make QC strategy and plan QC regularity. It's very helpful to realize this metrics into our laboratory daily analytical processes in order to produce precise test results.

\section{References}

1. Forsman RW. Why is the laboratory an afterthought for managed care organizations Clin Chem 1996; 42:813-6

2. Westgard JO, Westgard SA. Assessing quality on the Sigma scale from proficiency testing and external quality assessment surveys. Clin Chem Lab Med 2015; 53(10): 1531-5

3. Hens K, Berth M, Armbruster D, Westgard S. Sigma metrics used to assess analytical quality of clinical chemistry assays: importance of the allowable total error (TEa) target. Clin Chem Lab Med 2014; 52(7): 973-80.

4. X. Guo, T. Zhang, X. Gao, P. Li, T. You, Q.Wu Sigma metrics for assessing the analytical quality of clinical chemistry assays: a comparison of two approaches Biochem Med (Zagreb) 2018;28(2):020708

5. Westgard JO, Westgard SA. Assessing quality on the Sigma scale from proficiency testing and external quality assessment surveys. Clin Chem Lab Med 2015;53:1531-5. https:// doi.org/10.1515/cclm-2014-1241.

6. Westgard JO, Bayat H, Westgard SA. Planning risk-based SQC schedules for bracketed operation of continuous production analysers. Clin Chem 2018;64:289-96. https://doi. org/10.1373/clinchem.2017.278291

7. Westgard JO, Westgard SA. Quality control review: implementing a scientifically based quality control system. Ann Clin Biochem 2016;53:32-50. https://doi. org/10.1177/0004563215597248

8. Singh B, Goswami B, Gupta VK, Chawla R, Mallika V. Application of sigma metrics for the assessment of quality assurance in clinical biochemistry laboratory in India: a pilot study. Ind J Clin Biochem 2011;26:131-5. https://doi. org/10.1007/s12291-010-0083-1

9. Hens K, Berth M, Armbruster D, Westgard S. Sigma metrics used to assess analytical quality of clinical chemistry assays: importance of the allowable total error (TEa) target. Clin Chem Lab Med 2014; 52(7): 973-80.

37 | P a g e 
10. Farr AJ, Freeman KP. Quality control validation, application of sigma metrics, and performance comparison between two biochemistry analyzers in a commercial veterinary laboratory. J Vet Diagn Invest 2008; 20(5): 536-44.

11. Coskun A, Inal T, Unsal I, Serteser M. Six Sigma as a Quality Management Tool: Evaluation of Performance in Laboratory Medicine. Quality Management and Six Sigma 2010; 247-61.

12. Paolo C, Plebani M. Errors in a Stat Laboratory: Types and Frequencies 10 Years Later. Clin Chem 2007; 53(7): 1338-42

13. Huysal K, Budak YU. Application of sigma metrics for the assessment of quality assurance using theMQ-2000 PT HbA1c analyzer. Biochem Med (Zagreb). 2015; 25(3): 416-20.

14. Westgard JO, Klee GG. Quality management. In: Burtis CA, Ashwood ER, Bruns DE, eds. Tietz textbook of clinical chemistry and molecular diagnostics St. Louis, MO: Elsevier Saunders, 2006: 485-529.

15. Ricos C, Alvarez V, Cava F, Garcia-Lario JV, Hernandez A et al. Current databases on biological variation: pros, cons and progress. Scand J Clin Lab Invest 1999; 59: 491-500

16. Westgard JO. Six Sigma quality design and control. Westgard QC, Inc, Madison.

17. Singh B, Goswami B, Gupta VK, Chawla R, Mallika V. Application of sigma metrics for the assessment of quality assurance in clinical biochemistry laboratory in India: a pilot study. Ind $\mathrm{J}$ Clin Biochem 2011;26:131-5. https://doi. org/10.1007/s12291-010-0083-1

18. Harry M, Schroeder R, eds. Six sigma: the breakthrough management strategy revolutionizing the world's top corporations. Bantam Doubleday Dell Audio, 2000.

19. Ercan M, Bogdaycio lu N, Akbulut ED, O uz E, Top cuo lu immunassay tests with six sigma methodology. Clin Chem Lab Med 2015; 53, Special Suppl, pp S1-S1450

20. Gulbahar O, Arslan B, Sen B, Cingirt M, Y1lmaz SN. Evaluation of thyroid function tests in our laboratory by using six sigma analysis. Turkish Journal of Biochemistry 2015; 40 (S1).

21. Aksoy N, Tekin NH, Bireroğlu N, Serin NO. Application of sigma metrics for immunoassay tests. Clin Chem Lab Med 2014; 52, Special Suppl, pp S1-S1760.

22. Nanda SK, Ray L. Quantitative application of sigma metrics in medical biochemistry. J Clin Diagn Res 2013;7:2689-91. https://doi.org/10.7860/JCDR/2013/7292.3700

\section{Notes}

Note 1. The submission is original.

Note 2. The submission is not being considered elsewhere.

Note 3. There is no conflict of interests and, the authors agree to grant the journal for the first editing / publishing rights upon the acceptance of the article. 